\title{
Letters
}

All letters are subject to editing and may be shortened. General letters can be sent to bjgpdisclarcgp.org.uk (please include your postal address for publication), and letters responding directly to BJGParticles can be submitted online via eLetters. We regret we cannot notify authors regarding publication.

For submission instructions visit: bjgp.org/letters

\section{Appraisal, wellbeing, and pandemics: why a focus on wellbeing is always warranted}

Doctors are human beings, with personal and professional needs. ${ }^{1}$ Many have spent the pandemic supporting others with little support for themselves. The restart of appraisals offers protected time to have a confidential reflexive conversation with a well-trained peer. The rebalanced 'Appraisal 2020' process $^{2}$ minimises the pre-appraisal paperwork and recognises the impact of the pandemic. We urge doctors to seize this opportunity to make their appraisals valuable and ensure that their investment of time delivers maximum benefit to themselves and their patients.

A focus on wellbeing in appraisal is always warranted. In the World Medical Association Declaration of Geneva, doctors pledge: 'I WILL ATTEND TO my own health, well-being, and abilities in order to provide care of the highest standard. 'A doctor who is unwell cannot give their best care to patients - yet many doctors do not prioritise maintaining their own health and wellbeing. The risk of burnout for doctors was high even before the pandemic. Appraisal, as a process reaching all, is a proactive way to offer a safe place to discuss any concerns and be signposted to resources as needed.

Doctors should understand the code of conduct that defines the limits of professional confidentiality in any setting. If a doctor discloses a risk to personal or patient safety, appropriate action must be taken immediately to protect the vulnerable. An appraisal would be stopped - but so would a casual coffee-room conversation. Sensitive topics are frequently discussed at appraisal without being recorded. The written summary should always be mutually agreed before being signed off. The training for Appraisal 2020 reminds appraisers of this and emphasises the importance of creating a confidential safe space for support.

The core purpose of appraisal is not to revalidate. Appraisal cannot be 'failed'. Its published purposes ${ }^{2,3}$ are clearly supportive and developmental. Most doctors re-license without difficulty by demonstrating their continued competence through appraisal. An absence of concerns has been positively confirmed through appropriate clinical governance but they remain unaware of this aspect of the regulatory process.

Susanne R Caesar,

GP, Academy of Medical Royal Colleges. Email: susi.caesarlanhs.net

Graham Layer,

Consultant General Surgeon, Academy of Medical Royal Colleges.

Stephen Barasi,

Lay representative, Faculty of Medical Leaders and Managers.

\section{Competing interests}

Dr Caesar and Professor Layer are doctors subject to appraisal and revalidation. Dr Caesar was the Chair, Professor Layer the Vice-Chair, and Dr Barasi one of the lay representatives on the Academy of Medical Royal Colleges Professional Development Committee Medical Appraisal 2020 Task and Finish Group, which worked with key stakeholders to define the new process for the restart of appraisals, with a reduction in the required pre-appraisal documentation and a rebalanced focus on support, development, and the wellbeing of doctors in the context of the pandemic.

\section{REFERENCES}

1. McCartney M, Tzortziou Brown V. Appraisal, wellbeing, and pandemics: is a focus on wellbeing now warranted? Br J Gen Pract 2020; DOI: https:// doi.org/10.3399/bjgp20X712697.

2. Academy of Medical Royal Colleges. Medical appraisal guide 2020. London: AoMRC, 2020. https://www.aomrc.org.uk/wp-content/ uploads/2020/09/Medical_appraisal_guide_ covid19 0820.pdf (accessed 10 Nov 2020).

3. NHS Revalidation Support Team. Medical appraisal guide: a guide to medical appraisal for revalidation in England. NHS England, 2013. https://www.england.nhs.uk/revalidation/ wp-content/uploads/sites/10/2014/02/rst-medicalapp-guide-2013.pdf (accessed 10 Nov 2020)

DOI: https://doi.org/10.3399/bjgp20X713585

\section{Appraisal and} revalidation - time for a critical look?

The authors do an excellent job of making us think. ${ }^{1}$ I agree that the annual appraisal session is totally inappropriate for enquiry into general wellbeing etc.

Given that NHS general practice spends a lot of money and time on a process that has never, to my knowledge, been subjected to critical review, might this be a good time to look closely at the effectiveness of appraisal and revalidation?

Declan P Fox,

Semi-retired family physician, Tignish Health Centre, Tignish, Prince Edward Island. Email: declanfoxahotmail.com

\section{Competing interests}

I worked for several years in Canadian general practice and one of my motivators was to escape the evidence-free zone of appraisal and revalidation. I make my views clear to anyone interested in hearing them but have never received any type of monetary reward for that.

\section{REFERENCE}

1. McCartney M, Tzortziou Brown V. Appraisal, wellbeing, and pandemics: is a focus on wellbeing now warranted? Br J Gen Pract 2020; DOI: https:// doi.org/10.3399/bjgp20X712697.

DOI: https://doi.org/10.3399/bjgp20X713597

\section{When is it safe to return to exercise post-COVID-19?}

$A^{\prime}$ Court et al suggest that patients with 'mild' COVID-19 illness, and who are asymptomatic, do not need to restrict exercise. ' While this seems to be a straightforward distinction, new evidence on 'Long COVID' presentations even in patients with 'mild' illness is starting to raise questions on how we define the severity of COVID illness. The National Institute 